\title{
BMJ Open Using a system dynamics model to study the obesity transition by socioeconomic status in Colombia at the country, regional and department levels
}

\author{
Jose D Meisel (D) , ${ }^{1}$ Angie M Ramirez, ${ }^{1}$ Valentina Esguerra, ${ }^{2}$ Felipe Montes, ${ }^{2}$ \\ Ivana Stankov, ${ }^{3}$ Olga L. Sarmiento, ${ }^{4}$ Juan A Valdivia ${ }^{5,6}$
}

To cite: Meisel JD,

Ramirez AM, Esguerra V, et al. Using a system dynamics model to study the obesity transition by socioeconomic status in Colombia at the country, regional and department levels. BMJ Open 2020;10:e036534. doi:10.1136/ bmjopen-2019-036534

- Prepublication history and additional material for this paper are available online. To view these files, please visit the journal online (http://dx.doi. org/10.1136/bmjopen-2019036534).

Received 18 December 2019 Revised 17 April 2020 Accepted 28 April 2020

Check for updates

(C) Author(s) (or their employer(s)) 2020. Re-use permitted under CC BY-NC. No commercial re-use. See rights and permissions. Published by BMJ.

For numbered affiliations see end of article.

Correspondence to

Dr Jose D Meisel;

jd.meisel28@uniandes.edu.co

\section{ABSTRACT}

Objective We study the obesity transition by socioeconomic status (SES), gender and age within the Colombian urban population at the country, regional and department levels.

Design The study is informed by cross-sectional data from the 2005 and 2010 ENSIN survey. We used these data to develop a system dynamics model that simulates the dynamics of obesity by body mass index (BMI) categories, gender and SES at the country, regional and department levels from 2005 to 2030.

Participants The sample size of the 2005 ENSIN comprised 8515 children younger than 5 years, 32009 children and adolescents aged 5-17 years and 48056 adults aged 18-64 years. In 2010, the corresponding numbers were 11368,32524 and 64 425, respectively. Primary and secondary outcome measure The obesity prevalence ratio and prevalence rates for each BMI category.

Results The results show, at the country level, transitions from overweight to obesity were projected to increase sharply among lower SES adults, particularly among women, suggesting that these groups will undergo an obesity transition by 2030. The model projections also indicate that the regions of Colombia are in different stages of the obesity transition. In the case of women, five out of the six regions were expected to undergo an obesity transition by SES over time. For men, only one region was expected to undergo an obesity transition. However, at the department level, trends in the burden of obesity varied. Conclusions We evidence that the Colombian population could be experiencing an obesity transition where the increase in the GDP could be related to shifts in the burden of obesity from higher to lower SES, especially in women. These patterns support the need for policy planning that considers SES and gender, at the national and subnational levels, as important determinants of overweight and obesity among adults in Colombia.

\section{INTRODUCTION}

Obesity has become a global epidemic with at least 2.8 million deaths each year attributable to overweight and obesity. ${ }^{1}$ Obesity and overweight are associated with a range of noncommunicable diseases (NCDs) including
Strengths and limitations of this study

- To our knowledge, this is the first system dynamics (SD) model to explore the obesity transition by age, gender and socioeconomic status (SES) at the national and subnational level.

- The SD model has the capacity to incorporate a realworld ageing population structure from an upper middle-income country to dynamically explore the relationship between gross domestic product (GDP), and overweight and obesity prevalence, by gender and SES.

- Our study focuses only on GDP per capita as the main indicator of economic development at the country, region and department levels. This is the only indicator we had with available data across all time points and at both the national and subnational levels.

- Transference rates (TRs) between body mass index (BMI) categories were estimated using two data points, and we assumed no variation in mortality rates across BMI categories because these data were not available.

- Our model assumes that the estimated TRs between $\mathrm{BMI}$ categories do not change over time.

cardiovascular diseases, cancer, diabetes and chronic respiratory diseases. These NCDs are the leading global cause of death $(70 \%$ of deaths worldwide), ${ }^{2}$ especially in low-income and middle-income countries (LMICs). ${ }^{3}$

Studies of socioeconomic status (SES) and obesity have shown that LMICs are facing an obesity transition, which sees the burden of obesity shift towards the lowest SES group, particularly in women, as the economic development level of a country increases. ${ }^{4-7}$ Growing evidence suggests that several countries in Latin America and the Caribbean are experiencing an important and rapid obesity transition ${ }^{8}$ (eg, Chile, ${ }^{10}$ Brazil, $^{11}{ }^{12}$ Colombia, ${ }^{13-15}$ Mexico $^{16}$ and Argentina ${ }^{17}$ ). These findings have been 
echoed most recently by Jaacks et $a l,{ }^{18}$ who suggest that some Latin American countries (eg, Mexico, Colombia and Brazil) have experienced an obesity transition. In 1975 , these countries were in a stage characterised by a higher prevalence of obesity in women compared with men. In 2016, these countries had entered a new stage that is characterised, mainly, by a reduction in the difference in obesity prevalence, by SES, among women.

This paper focuses on Colombia because it has experienced significant increases in the gross domestic product (GDP) over the past decade (GDP increased from US\$ 145.181 billion in 2005 to US\$ 293.482 billion $^{19}$ in 2015). Additionally, Colombia has high social inequality that allows for the categorisation of the population into differentiated socioeconomic groups. This socioeconomic differentiation makes it especially relevant for the study of obesity transition patterns. According to the World Bank's GINI index, Colombia is ranked the fourth most unequal country in Latin America. ${ }^{20}$ Moreover, there is evidence that Colombia may be undergoing an obesity transition both at the country and regional levels. According to the 2005 and 2010 'Encuesta Nacional de la Situación Nutricional en Colombia' (ENSIN) survey, ${ }^{21} 22$ at the country level, there was a higher increase in the prevalence of obesity in the lowest wealth index (WI) quintile compared with the highest WI quintile for children, adolescents and adults. These patterns, however, differ importantly by region and department levels but have not been evaluated. Identifying obesity transition patterns at the national and subnational levels is key to developing more targeted and effective interventions.

Furthermore, obesity can be tackled as a complex adaptive system $^{23}$ due to the global scope, heterogeneous patterns, wide-ranging causes and impacts and the absence of a single solution. Given the dynamic and complex nature of obesity, calls have been made for the use of complex systems methods to better understand and address the public health challenges posed by the obesity epidemic. ${ }^{24}$ To date, however, most studies focused on understanding the relationship between economic development and obesity across the socioeconomic spectrum have applied statistical models (regression-based approaches). ${ }^{5-7}$ Studies employing complex systems approaches to understand obesity and its associated factors have used methods, such as system dynamics (SD), ${ }^{15}$ 25-29 network analysis ${ }^{30-34}$ and agent based modelling. ${ }^{35-38}$ The body of literature applying complex system approaches to investigate the dynamics of obesity by SES and gender on the other hand remains limited. The only such study that has been conducted in a Latin American country has not accounted for diversity at the sub national level. ${ }^{18} 39$

At the population level, various SD models have been proposed to study the dynamics of obesity, for example: the nutritional stage dynamics between body mass index (BMI) categories by age and SES, ${ }^{15}$ the energy imbalance gap (EIG) by gender and racial subpopulations among US adults, ${ }^{26}$ weight gain and obesity in women of reproductive age and its impact on family building, ${ }^{25}$ the distributions of weight and SES and the transitions between these states over time in $\mathrm{USA}^{29}$ and the effect of changes in the eating behaviour of British children (aged $2-15$ years) on weight and obesity. ${ }^{27}$ These studies were developed to monitor the impact of health interventions and to evaluate different policy scenarios seeking to curb obesity prevalence.

Although different SD models have been developed to study obesity dynamics at the population level, to date, there has been no attempt to understand this complex system at the national and sub national levels. Characterising obesity dynamics at these levels could afford important insights relevant to the development of targeted obesity prevention initiatives by age, gender and SES. This study seeks to bridge this gap by applying SD modelling to investigate obesity transitions by SES, gender and age, along with their relationship to GDP,within the Colombian urban population at the country, regional and department levels over time. Specifically, we seek to identify in which regions and departments of Colombia the burden of obesity have shifted towards the lower SES populations and how these shifts relate to regional level and department level GDP.

\section{METHODS}

\section{Model overview}

To analyse the obesity dynamics at the national and subnational levels, we developed a population-level SD model and used a heuristic to estimate the transition rates (TRs) between BMI categories by age, gender and SES using data obtained, mainly from the 2005 and 2010 ENSIN for individuals aged 0-64 years, which were based on a validated and calibrated model. ${ }^{1540}$ Specifically, tests assessing the suitability of the SD model showed that the model was robust and that the simulated behaviour was consistent with the expected results for the estimated prevalence rates for each BMI category and age. ${ }^{15} \mathrm{We}$ estimated the TRs between BMI categories by age, gender and SES and applied the SD model to simulate and investigate the obesity dynamics by SES within the Colombian urban population from 2005 to 2030 . We only simulated the urban population because the highest SES group in rural areas is poorly represented (ie, less than $0.05 \%$ of the population). ${ }^{41}$

\section{Data}

The study is based on cross-sectional data obtained from the 2005 and 2010 ENSIN. ${ }^{21}{ }^{22}$ The ENSIN used a multistage, stratified, population-based cluster sampling design that included both household and individual components. The questionnaire was administered in the home by female interviewers equipped with computerassisted personal interview technology. The sample for 2005 comprised 8515 children younger than 5 years, 32 009 children and adolescents aged 5-17 years and 48 056 adults aged $18-64$ years. In 2010, the corresponding numbers for the sample were 11 368, 32524 and 64 425, 
Table 1 Data sources used in the model

\begin{tabular}{|c|c|}
\hline Item & Data source \\
\hline \multicolumn{2}{|c|}{ Prevalence rates by BMI category, age and WI at country, regional and department levels } \\
\hline $\begin{array}{l}\text { BMI for age and gender } z \text {-score for children and adolescents aged 0-17 } \\
\text { years by WI }\end{array}$ & National Nutrition Survey (ENSIN), 2005. ${ }^{21}$ \\
\hline BMI category prevalence by age, gender and WI for adults & National Nutrition Survey (ENSIN), 2010. ${ }^{22}$ \\
\hline \multicolumn{2}{|l|}{ Population composition at country, regional and department levels } \\
\hline Population size by age, gender and WI & $\begin{array}{l}\text { Colombian National Department of Statistics (DANE). Estimations } \\
\text { and population projections for } 1985-2020 .{ }^{56}\end{array}$ \\
\hline Mortality rates by age group and gender & DANE. Vital Statistics (2005). ${ }^{45}$ \\
\hline \multirow[t]{2}{*}{ Fertility rate } & World Data Bank. World Development Indicators (1960-2014). ${ }^{57}$ \\
\hline & $\begin{array}{l}\text { Projections for 2015-2030. Forecast series using the Holt-Winters } \\
\text { no seasonal method in EViews } 10 \text { (Quantitative Micro Software, } \\
\text { LLC). }\end{array}$ \\
\hline
\end{tabular}

Classification of individuals by BMI category

Height-for-age z-score and BMI for age and gender z-score cut-off points for children and adolescents aged $0-17$ years:

Not overweight: BMI for age and gender $z$-score $\leq 1 \mathrm{SD}$

Overweight: BMI for age and gender $z$-score $>1$ SD and $\leq 2$ SD

WHO child growth standards. ${ }^{42}$

Obese: BMI for age and gender z-scores $>2$ SD

BMI category cut-points for adults aged 18-64 years:

Not overweight: BMl $<25 \mathrm{~kg} / \mathrm{m}^{2}$

Overweight: $\mathrm{BMI} \geq 25$ and $<30 \mathrm{~kg} / \mathrm{m}^{2}$

Obese: $\mathrm{BMI} \geq 30 \mathrm{~kg} / \mathrm{m}^{2}$

SES indicator

Wealth index quintile

National Nutrition Survey (ENSIN), 2005. ${ }^{21}$

National Nutrition Survey (ENSIN), 2010. ${ }^{22}$

Economic development level indicator

GDP per capita at regional and department level

WHO cut-off points. ${ }^{44}$

DANE. GDP per capita. ${ }^{49}$

Projections for 2017-2030. Forecast series using the double exponential smoothing method in EViews 10 (Quantitative Micro

Software, LLC).

BMI, body mass index; DANE, Colombian National Department of Statistics; DHS, Demographic and Health Surveys; GDP, gross domestic product; SES, socioeconomic status; WI, wealth index.

respectively. All the data used in the model were obtained from public sources and are fully available in online supplementary information 1-3. Table 1 describes the data sources used in the model.

\section{Patient and public involvement statement}

Due to the very technical methods required to do the data analysis, patients and/or the public were not involved in the design, or conduct, or reporting, or dissemination plans of this research.

\section{Model to assess the obesity dynamics}

We used a population-level SD model to assess the obesity dynamics by SES at the national and subnational levels. The model is characterised by ageing chains, which are robust structures commonly used in SD models to understand the evolution of ageing in a population. They are especially important when population data are sparse. Our population-level SD model includes ageing chains for three BMI categories (not overweight, overweight and obese), in which the population aged $0-59$ years was divided into age groups of 5 years. People in the 60-64 age group are not represented in the SD model. This is because 2010 prevalence rates by BMI categories for the age group 65-69 years, which are required for a reliable estimate of the TRs for this age group, are unavailable. Individuals were classified into the three BMI categories based on WHO standards and references (table 1). ${ }^{42-44}$ Additionally, in the SD model structure, we included births and deaths (the mortality rates differed among the age groups and gender) for each cohort. ${ }^{40}$ Given our interest in investigating the obesity dynamics by SES, we assumed the same mortality rate for each BMI category in each age 
group. The net migration rate (NMR) is another variable that could be included in an ageing chain structure. At the country level, NMR ranges from $-0.23 \%$ to $-2.65 \%$ for the different age groups of 5 years. At the department level, the NMR ranges from $-0.18 \%$ to $-1.47 \%$ for negative values and from $0.18 \%$ to $1.38 \%$ for positive values among the different age groups and departments. Nevertheless, we did not include net migration as a variable in the SD model because, to date, there are no data for Colombia that relate to mortality rates or net migration patterns by BMI category. ${ }^{45} 46$

To stratify the population by SES group, we used the World Bank's WI. ${ }^{47}$ It is a validated index that allows categorisation of the population into socioeconomic groups and captures quality of life markers. ${ }^{48}$ We grouped the WI quintiles into three socioeconomic groups: the lowest and second quintiles (lowest SES group), the middle quintile (middle SES group) and the fourth and highest quintiles (highest SES group).

To examine the obesity transition by SES over time, we compared the lowest SES group with the highest SES group using the simulated obesity prevalence ratio (PR), which is a measure of the ratio of the probability, for each gender $j$, of being obese in the lowest SES group to the probability of being obese in the highest SES group for individuals aged 20-59 years, according to the following equation:

$$
P R_{i}(t)=\frac{\frac{\sum_{i=4}^{11} O_{i, j, 1}(t)}{\sum_{i=4}^{11}\left(N_{i, j, 1}(t)+W_{i, j, 1}(t)+O_{i, j, 1}(t)\right)}}{\sum_{i=4}^{11} O_{i, j, 3}(t)}
$$

Where $t$ represents the time in years of the simulation; $N_{i, j, 1}, W_{i, j, 1}$ and $O_{i, j, 1}$ represent not overweight, overweight and obese individuals with the lowest SES, respectively, in age group $i$ and gender $j$, and $N_{i, j, 3,}, W_{i, j, 3}$ and $O_{i, j, 3}$ represent not overweight, overweight and obese individuals of higher SES, respectively, in age group $i$ and gender $j$. A PR value greater than 1 indicates that the obesity prevalence of the lowest SES group is greater than the obesity prevalence of the highest SES group. We assumed that individuals did not change SES group membership because there are no available data from which TRs between SES groups can be derived for individuals in Colombia at the country, regional or department level. Additionally, we used the GDP per capita to study the relation between the level of economic development and obesity by SES over time. To analyse the relation between obesity PRs by SES and the economic development level over time, we forecasted the GDP per capita from 2017 to 2030 by applying a double exponential smoothing method to GDP data from the DANE. ${ }^{49}$ The full description of the SD model is available in the online supplementary information 3, pp. 3-5.

We used a similar SD model to simulate the obesity dynamics at the regional and department levels. At the regional level, we studied the obesity dynamics by SES and gender in six regions: Atlántica, Bogotá, Central, Oriental, Orinoquía y Amazonia and Pacífico. At the department level, we only studied the obesity dynamics by SES in 29 of 32 departments of Colombia (a map of Colombia by regions and departments is available in the online supplementary information 3, pp. 8). The model could not be used to simulate Choco, Vaupes and Vichada departments because reliable TR estimates could not be generated for these departments due to limitations in the ENSIN data. Similarly, data sparsity for the Putumayo, Amazonas, Guainía and Guaviare departments made it impossible to estimate the TRs for the highest SES group. Therefore, for these departments, we assessed the obesity dynamics by SES, by comparing the lowest SES group with the middle SES group using the PR of obesity. Additionally, the forecasts of the GDP per capita for the Arauca, Casanare, Meta and Putumayo departments were not used because these departments had an unstable GDP per capita growth over time and the forecasts therefore did not have a good fit. Finally, at the department level, we did not include gender to simulate the obesity dynamics and to estimate the TRs between BMI categories due to limitations in the ENSIN data when we divided the population into BMI categories, gender and SES. The data processing was conducted using SAS V.9.3 and Mathematica 11 (Wolfram Research, Inc) while all simulations were run on iThink 9.0.2 (ISEE Systems, Inc).

\section{RESULTS}

\section{Obesity dynamics at country level by gender, age and SES}

The results of the heuristic show that estimated TRs towards overweight $(\tau 1)$ and obese $(\tau 2)$ were larger among individuals in the lower SES group, particularly women (mean $\tau 1=0.0195$ and mean $\tau 2=0.0059$, for men; and mean $\tau 1=0.0245$ and mean $\tau 2=0.0125$, for women), than among those in the middle (mean $\tau 1=0.0159$ and mean $\tau 2=0.0037$, for men; and mean $\tau 1=0.0164$ and mean $\tau 2=0.0095$, for women), or higher SES groups (mean $\tau 1=0.0143$ and mean $\tau 2=0.0061$, for men; and mean $\tau 1=0.0169$ and mean $\tau 2=0.0041$, for women) (figure 1A-D). For boys aged 0-4 years, the TRs to overweight $(\tau 1)$ and obese $(\tau 2)$ were larger in the highest SES than the other SES groups (figure 1A,C). For boys aged 10-14, the TR from obese to overweight ( $\tau 3)$ and from overweight to not overweight $(\tau 4)$ were larger in the middle and higher SES groups than in the lower SES group according to heuristic estimates. For girls aged 5-9 years, however, the TR from obese to overweight $(\tau 3)$ were larger in the middle and higher SES groups than in the lower SES group. For girls aged 0-4 years, the TR from overweight to not overweight $(\tau 4)$ were larger in the lower SES group than the other SES groups (figure 1E-H).

Simulation results show that children and adolescents aged 0-14 years (both boys and girls) will show no major changes in their BMI category distribution over time, across all SES populations. However, the burden of obesity is shifting towards the lower SES populations, especially 


\section{Men}

Transference rate $\left(\tau_{1}\right)$

A)

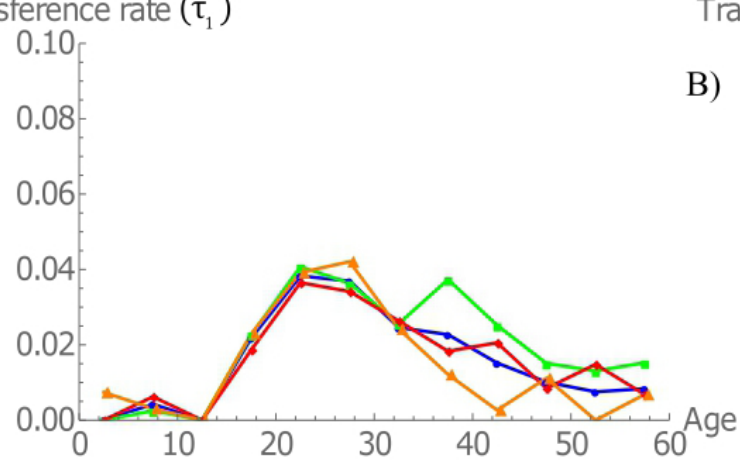

\section{Women}

Transference rate $\left(\tau_{1}\right)$

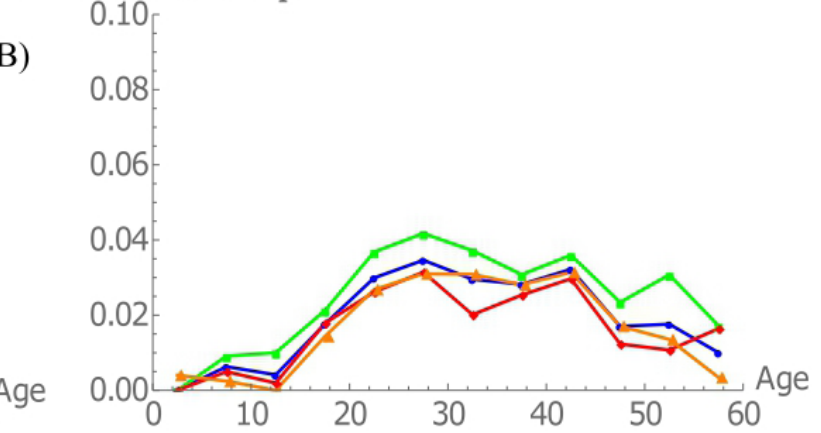

Transference rate $\left(\tau_{2}\right)$

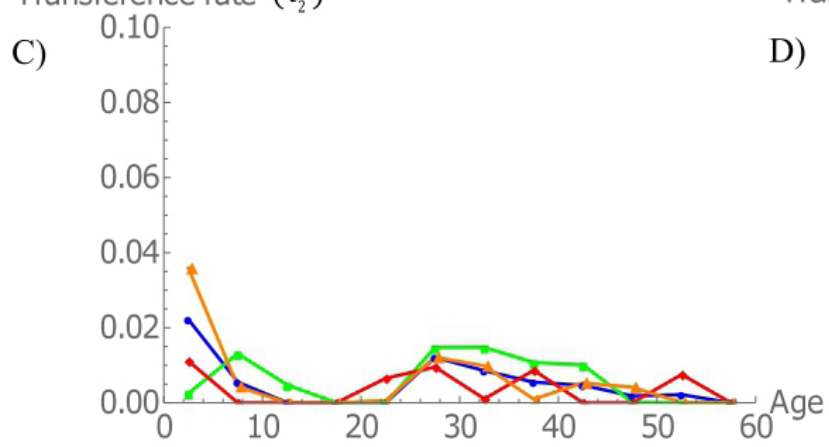

Transference rate $\left(\tau_{2}\right)$

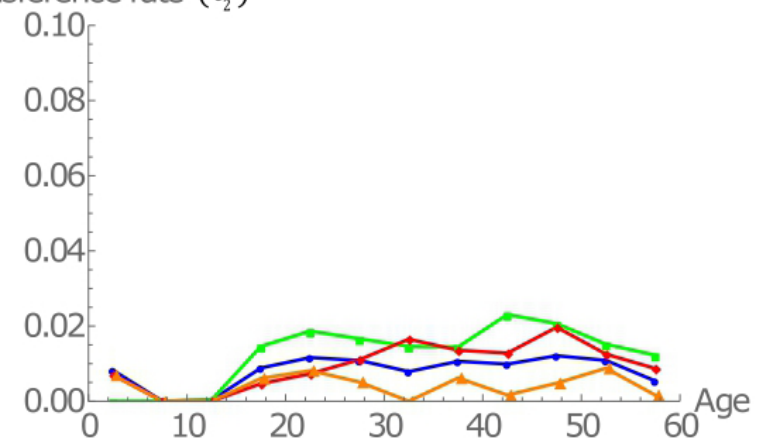

Transference rate $\left(\tau_{3}\right)$

E)

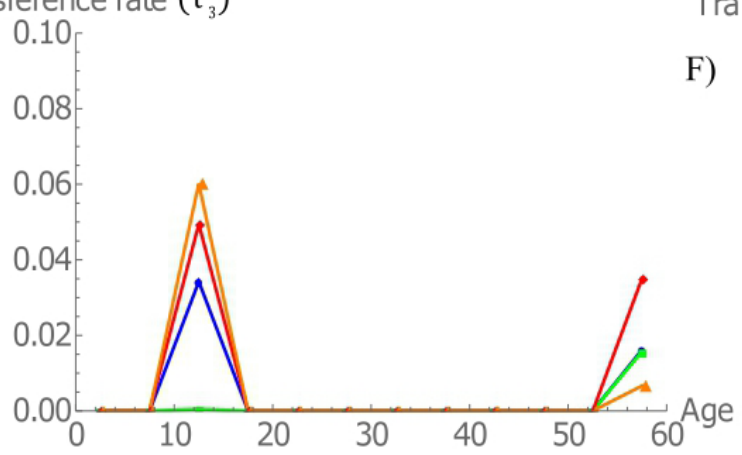

Transference rate $\left(\tau_{3}\right)$

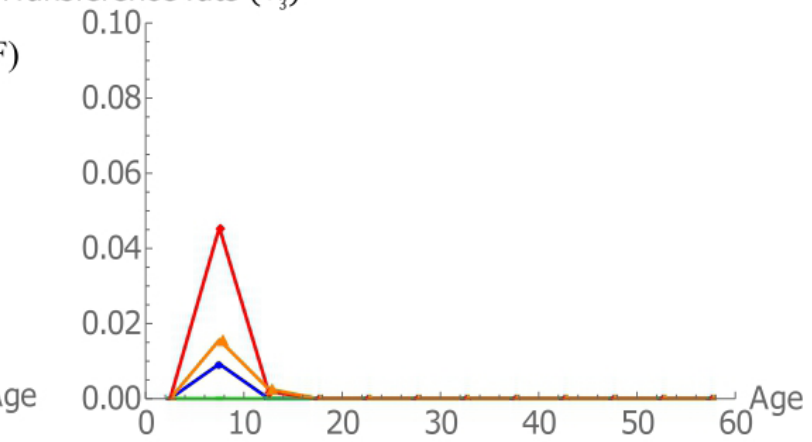

Transference rate $\left(\tau_{4}\right)$

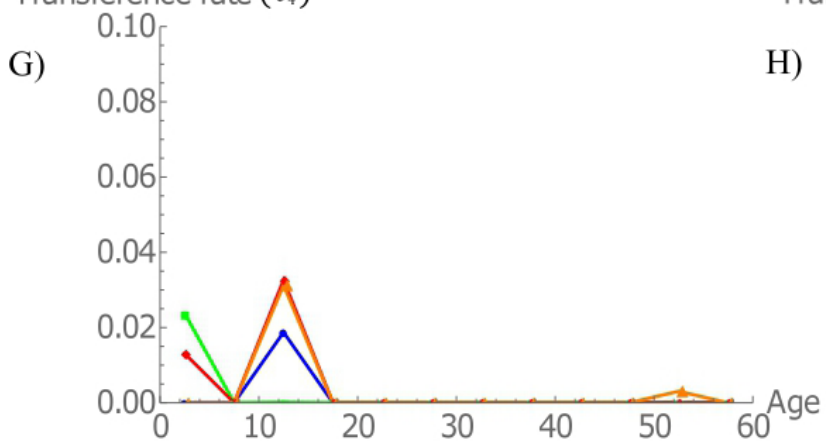

Transference rate $\left(\tau_{4}\right)$

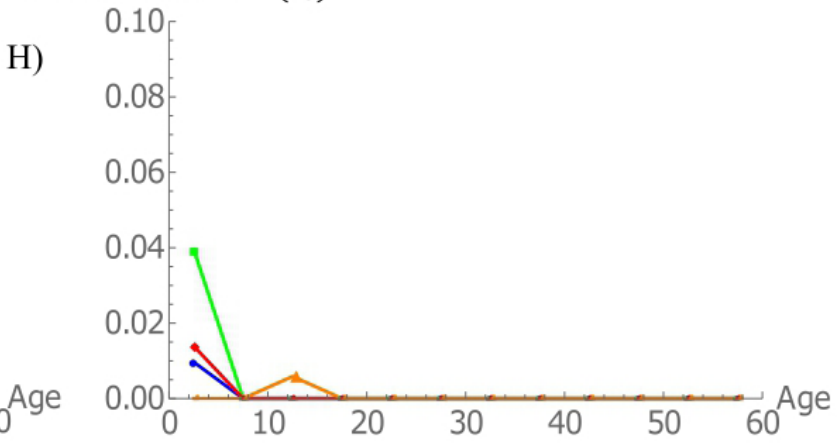

- Complete Population - Lower SES

- Middle SES

- Higher SES

Figure 1 Estimated transference rates between BMI categories by age and SES for men and women at country level. (A) Not overweight to overweight ( $\tau 1$ ) for men, (B) overweight to obese $(\tau 2)$ for men, (C) obese to overweight ( $\tau 3)$ for men and (D) overweight to not overweight $(\tau 4)$ for men. (E) Not overweight to overweight $(\tau 1)$ for women, (F) overweight to obese $(\tau 2)$ for women, $(G)$ obese to overweight $(\tau 3)$ for women and $(H)$ overweight to not overweight $(\tau 4)$ for women. BMl, body mass index; SES, socioeconomic status. 
Men
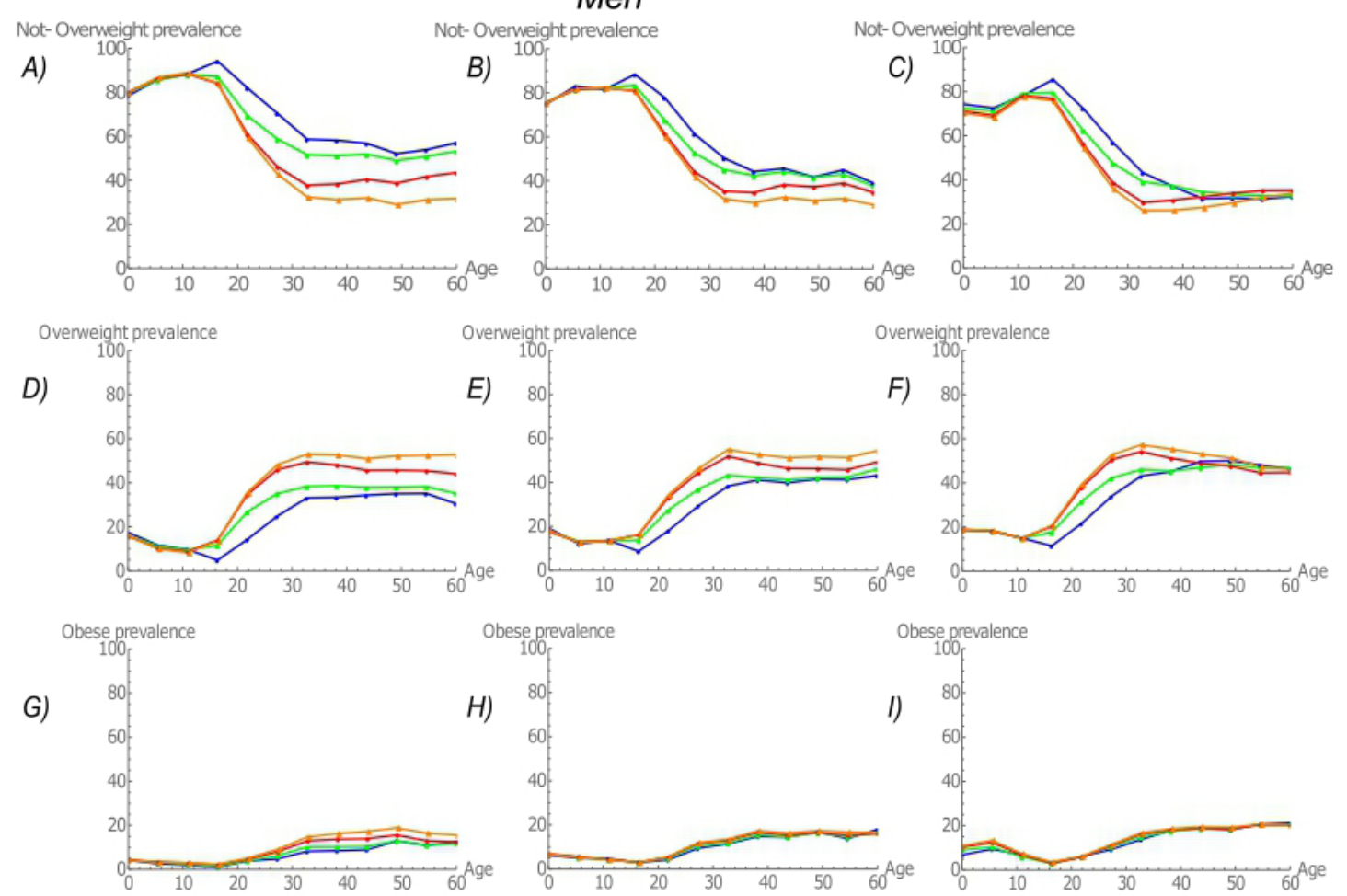

Women
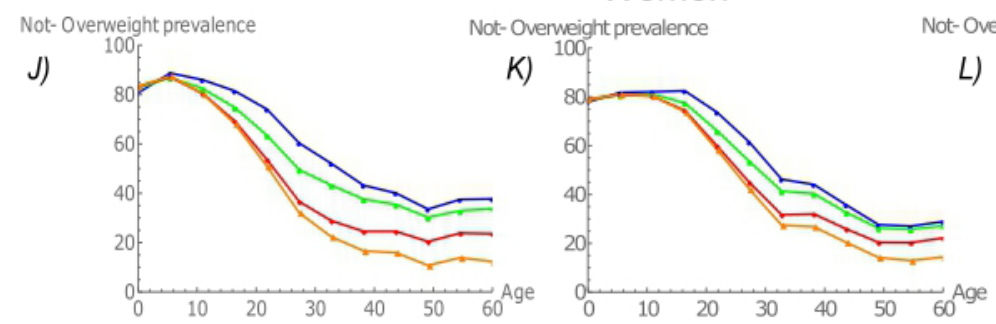

t- Overweight prevalence

)
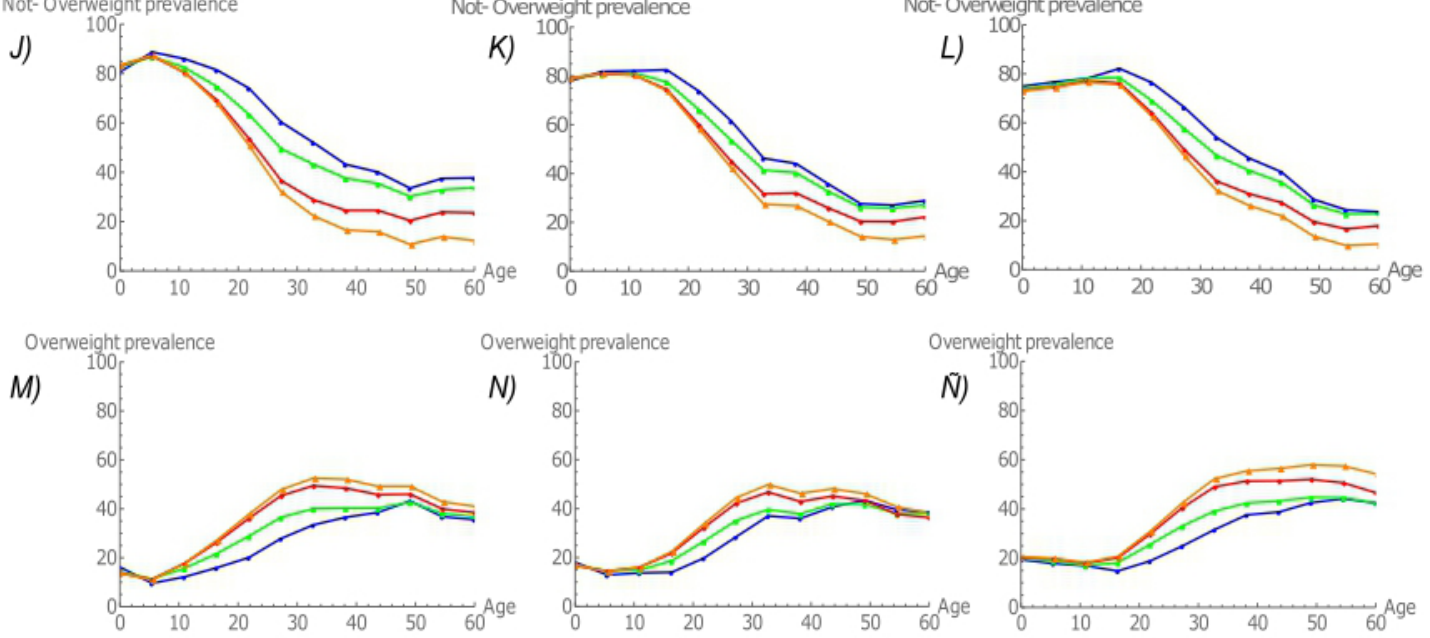

Overweight prevalence
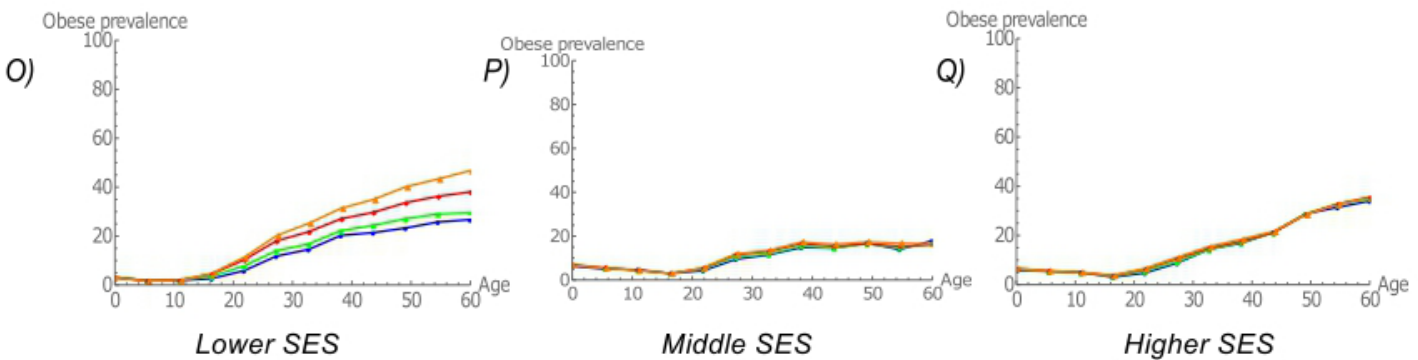

Figure 2 Estimated prevalence rates by BMI category, age, gender and SES group. For men: (A) Not overweight, lower SES; (B) not overweight, middle SES; (C) not overweight, higher SES; (D) overweight, lower SES; (E) overweight, middle SES; (F) overweight, higher SES; (G) obese, lower SES; (H) obese, middle SES; and (I) obese, higher SES. For women: (J) not overweight, lower SES; (K) not overweight, middle SES; (L) not overweight, higher SES; (M) overweight, lower SES; (N) overweight, middle SES; (Ñ) overweight, higher SES; (O) obese, lower SES; (P) obese, middle SES; and (Q) obese, higher SES. Blue=2005; green $=2010$; red $=2020$; orange $=2030$. 


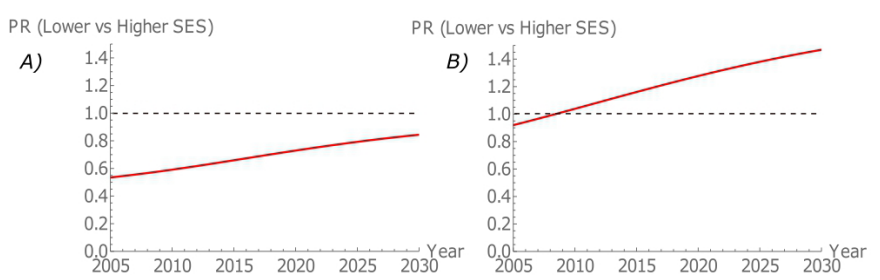

Figure 3 Obesity prevalence ratio (PR) among urban adults aged 20-59 years. (A) Men. (B) Women. SES, socioeconomic status.

among adults (figure 2). Between 2005 and 2030, men aged 14-59 years are moving towards overweight and obesity categories (figure 2A-C). Specifically, the prevalence of overweight among men aged 20-59 years in the lowest, middle and highest SES groups increased from $28.5 \%$ to $49 \%$, from $34.8 \%$ to $49.1 \%$ and from $40.8 \%$ to $50.6 \%$, respectively (figure 2D-F). Among obese men aged 20-59 years, the differences between SES groups were also striking with a lower, middle and higher SES increased from $7.9 \%$ to $13.6 \%$, from $11.9 \%$ to $14 \%$ and from $14.7 \%$ to $16.1 \%$, respectively (figure $2 \mathrm{G}-\mathrm{I}$ ). In the case of women aged 14-59 years, they are also moving towards overweight and obesity categories (figure 2J-L). Specifically, the prevalence of overweight among women aged 20-59 years in the lowest, middle and highest SES groups increased from $32.6 \%$ to $46.8 \%$, from $34.2 \%$ to $43.8 \%$ and from $33.8 \%$ to $50.2 \%$, respectively (figure $2 \mathrm{M}, \mathrm{N}$ and figure $2 \tilde{N}$ ). Among obese women aged 20-59 years, the differences between SES groups were even more prominent than in men with a lower, middle and higher SES increased from $13.8 \%$ to $29 \%$, from $19.1 \%$ to $26.6 \%$ and from $18.3 \%$ to $19.8 \%$, respectively (figure 2O-Q).

The simulated obesity PRs among urban men and women aged 20-59 years (figure 3) confirm that the burden of obesity among adults, especially women, tends to shift towards those with lower SES. In fact, we confirmed, for both men and women, that obesity in the lower SES population is increasing faster than obesity in higher SES populations. Despite these trends, however, for men, the burden of obesity is projected to remain greatest among individuals with higher SES, at least up to and potentially beyond 2030 .

\section{Obesity dynamics at region level by gender, age and SES}

The model projections further indicate that the regions of Colombia are in different stages of the obesity transition (figure 4). For men, the only region that was projected to experience an obesity transition was Orinoquia y Amazonia. However, the GDP per capita within this region increased only from 2005 to 2013 (percentage increase of $124.86 \%$ ), followed by a small decrease in the period between 2014 and 2016. In the Atlántica, Pacífica and Central regions, the PR of obesity increased more rapidly in the lowest SES group than the highest SES group as the GDP per capita increases. Nevertheless, according to our model, these regions were unlikely to experience an obesity transition by 2030. Bogotá and

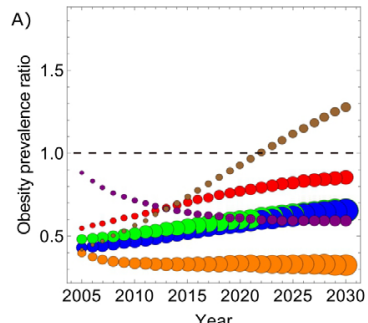

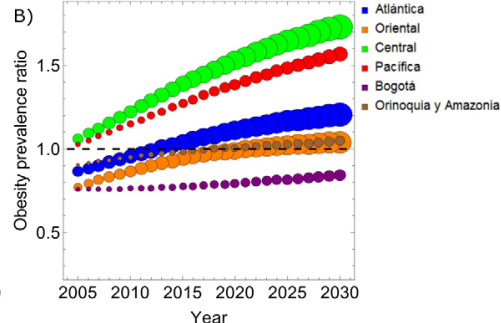

Year
Figure 4 Prevalence ratio of obesity (lower SES vs higher SES) among urban adults aged 20-59 years versus gross domestic product (GDP) per capita at regional level. Obesity prevalence ratios greater than 1 signal obesity transitions by SES. Bubble size based on the total GDP per capita for each region. We calculated the forecast of the GDP per capita from 2017 to 2030. (A) Men. (B) Women. SES, socioeconomic status.

Oriental regions were also not expected to undergo an obesity transition. In fact, the model's projections indicate that these two regions would likely follow an inverted trajectory compared with other regions in Colombia (figure 4A). In the case of women, in five out of the six regions (ie, Atlántica, Oriental, Central, Pacífico and Orinoquia y Amazonía), the burden of obesity was projected to shift towards populations with lower SES, as the GDP per capita increased. Our model projections also suggest that these regions were likely to experience an obesity transition (figure 4B). While the burden of obesity was also observed to shift towards populations with lower SES in Bogotá, women in this region were not projected to undergo an obesity transition, unlike those in the other regions (figure 4B).

\section{Obesity dynamics at department level by SES}

Akin to the model projections at the regional level, we observed that the departments of Colombia are also at different stages of the obesity transition (figure 5). In nine departments, we observed that the obesity PR increased more rapidly in the lowest SES group than in the highest SES group as the department's GDP per capita increased: Amazonas, Guanía, Cauca, Valle del Cauca, Boyacá, Antioquia, Tolima, Caldas and San Andres. In the departments of Santander, Atlántico, Bolívar, Norte de Santander, Cesar, La Guajira, Magdalena and Sucre the obesity PR increased more rapidly in the lowest SES group than in the highest SES group as the GDP per capita increased, though these departments were unlikely to experience an obesity transition according to model estimates. Similarly, in the departments of Arauca, Casanare and Putumayo, the PR of obesity increased more rapidly in the lower SES group than in highest SES group (for the period with useable GDP estimates), though no obesity transitions were apparent during the available years. However, in departments of Cundinamarca, Córdoba, Huila, Nariño, Quindío, Risaralda, Caquetá and Guaviare, the obesity PR increased more rapidly in the highest SES group than in the lowest SES group, despite increases in the GDP per capita (figure 5). Similarly, in the Meta department, 

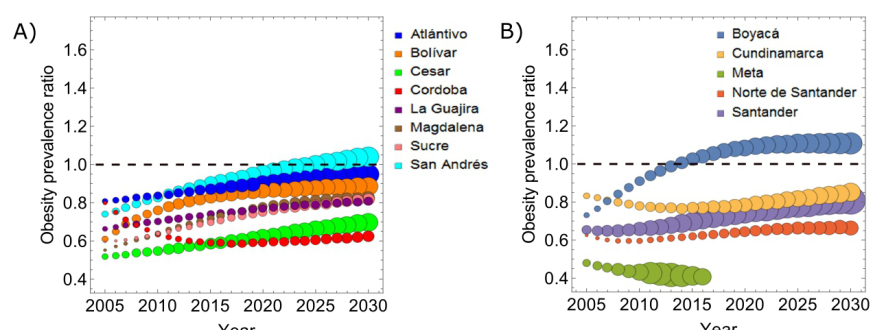

Yea

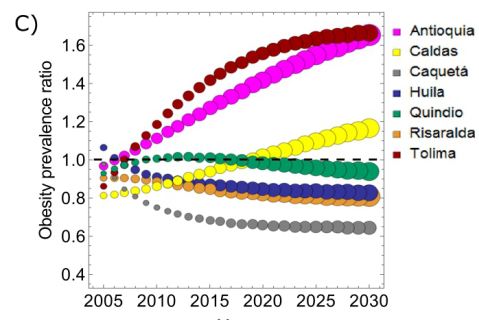

Year

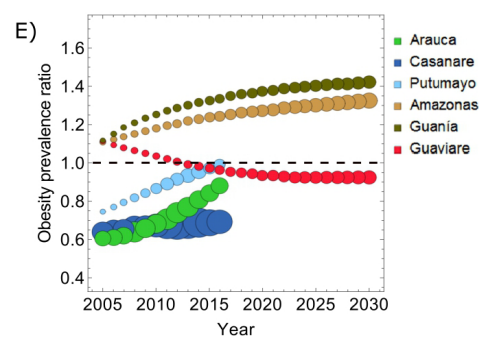

Figure 5 Prevalence ratio of obesity (lower SES vs higher SES) among urban adults aged $20-59$ years versus gross domestic product per capita at department level. Obesity prevalence ratios greater than 1 signal obesity transitions by SES. (A) Atlántica region. (B) Oriental region. (C) Central region. (D) Pacífica region. (E) Orinoquia y Amazonia region. Bubble size based on the gross domestic product per capita. We calculated the forecast of the GNP per capita from 2017 to 2030. GNP, gross national product; SES, socioeconomic status.

the obesity PR increased more rapidly in the higher SES group than in the lower SES group (for the period with useable GDP estimates).

\section{DISCUSSION}

The findings of this paper indicate that there exist substantial variations in the projected burden of obesity by gender, age and across the socioeconomic spectrum within and across the regions and departments of Colombia. At the country level, transitions from overweight to obesity were projected to increase sharply among lower SES adults, particularly among women, suggesting that these groups will undergo an obesity transition by 2030 . These patterns were also observed across most regions of Colombia where increases in GDP were predicted to shift the burden of obesity from higher to lower SES groups, also being most evident for women. Although several regions were projected to experience increases in GDP, men in only one region in Colombia (Orinoquia y Amazonia) were expected to undergo an obesity transition by SES over time. At the department level, trends in the burden of obesity were mixed. For some departments, the burden was projected to shift from higher to lower SES groups, with several of these departments expected to undergo an obesity transition. However, inverse trends were observed in other departments, where increases in GDP were accompanied by more rapid increases in obesity prevalence among higher compared with lower SES groups. These patterns support the need for policy planning that considers SES and gender, at the national and subnational levels as important determinants of overweight and obesity among adults in Colombia.

Our overarching finding that the burden of obesity is projected to shift towards lower SES populations, particularly among women, as GDP per capita increases, is consistent with previously published studies focusing predominantly on country-level trends. ${ }^{5-7} 9182950$ For example, a systematic review published in 2004, studying associations between SES and obesity in developing countries, found that the burden of obesity shifts to lower SES groups as a country's gross national product increases. ${ }^{5}$ Furthermore, our results also align with the findings of Jones-Smith et als study. ${ }^{51}$ The authors observed that while overweight and obesity remained most prevalent among higher income individuals in most countries, over time, the prevalence of obesity rose among those with the lowest income as GDP per capita increased. Most recently, using evidence from over 30 countries, Jaacks et al ${ }^{18}$ illustrated the different stages of the obesity transition, demonstrating that as the level of economic development increases, the prevalence of obesity is greater in populations with lower SES than in the higher SES, especially in women.

This paper also provides unique insights into how a system can demonstrate vastly different patterns and behaviour at different levels of aggregation. For example, increases in GDP were associated with obesity transition by SES at the country level and across most regions of Colombia, particularly among women. This patterning, however, was not consistently observed at the department level where seemingly only the departments that experienced sizeable increases in economic development, such as Amazonas, Guanía, Cauca, Valle del Cauca, Boyacá, Antioquia, Tolima, Caldas, San Andres, Santander, Atlántico, Bolívar, Cesar, La Guajira, Magdalena and Sucre, were projected to undergo an obesity transition by SES, as the GDP per capita increased. These findings are consistent with the study by Jaacks $e t a l,{ }^{18}$ which suggested that variations in obesity transitions at a subnational level may be explained by socioeconomic factors and inequalities. It is also possible that the observed differences across country/region and department levels are an artefact of our study's exclusive focus on GDP, the only indicator we had with available data across all time points and at the national and subnational levels. Perhaps other indicators, such as the Human Development Index (HDI) or education level, have a more robust relationship with the obesity transition across country, region and department levels. ${ }^{6}$ Another potential reason for the observed differences at the department level could relate to the 
fact that we were unable to model obesity dynamics by gender, due to data sparsity. Countries in LMIC particularly Latin American countries are very unequal and diverse. ${ }^{52}$ As such, the heterogeneity in obesity transitions should be taken into account in the planning of targeted interventions. This study is the first to provide insights at the subnational level.

The current analysis also has important policy implications. For Colombia, the results provides patterns of transition by SES and gender that are crucial to monitor the implementation of policies like the National Policy of Food and Nutrition Security and the obesity law (National law 1355/2009), which stipulates that schools should ensure fruit and vegetable availability, implement food education programmes and regulate the consumption of highly caloric foods and beverages. Both policies have intersectoral actions to control the broad spectrum of malnutrition and NCDs in Colombia. Furthermore, in regions like Amazonia \& Orinoquia and Atlántica, policies have principally been directed towards tackling undernutrition, but our results also underscore the potential importance of programmes aimed at controlling obesity transitions. In fact, policies in Colombia should account for the double burden mainly in low-income communities. ${ }^{53}$ In addition, our results also underscore the importance of programmes aimed at preventing obesity which could include physical activity (PA) promotion, healthy eating and tax schemes for sugar-sweetened beverages and ultra-processed foods. In this context, PA promotion programmes like the Hábitos y Estilos de Vida Saludable (HEVS; Healthy Life Habits) programme and the taxes on sugar-sweetened beverages are key initiatives. The HEVS programme, in which women are more likely to participate, provides free community-based PA classes for individuals across Colombia and has been shown to decrease BMI, waist circumference and hypertension. ${ }^{54}$ Lastly, simulations of the potential impact of a tax on sugar-sweetened beverages shows that it could reduce overweight and obesity prevalence particularly among low SES populations. ${ }^{55}$

The findings of this study should be considered in light of a few limitations. First, the accuracy of the model's predictions is limited given that the TRs between BMI categories could only be estimated using two data points: the 2005 and 2010 ENSIN survey. Future studies should validate model trends against survey data collected over a longer temporal window. Second, we assumed no variation in mortality rates across BMI categories because these data were not available. To this end, future data collection efforts should include more nuanced collection of mortality data and regular assessments of BMI by age, gender and WI at the national and subnational levels. Third, our model assumes that the estimated TRs between BMI categories do not change over time. Future extensions of the model should dynamically incorporate the impact of other factors, on temporal changes in BMI TRs and their effects on obesity PR projections by SES. Fourth, our study focuses on GDP per capita as the main indicator of economic development at the country, region and department levels. Future studies should explore other measures, such as HDI or education level, that may function as better indicators of social and economic development across all three spatial units. Fifth, given the purpose of the study and aims defined for the SD model, we focus on characterise obesity transition patterns by SES, gender and age at different levels over time. Nevertheless, it is important to study the effect that the intersectionality between SES and gender could generate in the dynamics of obesity and in the health system. Particularly, it could be important to study and characterise vulnerable population subgroups such as lower SES women who, based on the findings of our study, are increasingly transitioning from overweight to obesity. Therefore, future studies should focus on assess the overlapping categories of inequality that could be involved in the relationship between BMI categories, SES and gender. Finally, given our finding that trends in obesity transition vary across the national and subnational level, future studies should explore whether threshold effects in GDP could explain these observations, and whether indeed, there exist different critical points for transitions at the country, region and department levels.

\section{CONCLUSION}

Our model suggests that increases in GDP may be associated with shifts in the burden of obesity from higher to lower SES urban dwellers, especially lower SES women. According to the model's projections, by 2030, these shifts could signal obesity transitions among lower SES women. These patterns were consistently observed at the country level and across most regions in Colombia. There are several implications of these findings, including policy planning at different levels of government and the potential need to target population subgroups at greatest risk of obesity transition in the coming years.

\section{Author affiliations}

${ }^{1}$ Facultad de Ingeniería, Universidad de Ibague, Ibagué, Tolima, Colombia ${ }^{2}$ Department of Industrial Engineering, Social and Health Complexity Center, Universidad de los Andes, Bogota, Colombia

${ }^{3}$ Urban Health Collaborative, Dornsife School of Public Health, Drexel University, Philadelphia, Pennsylvania, USA

${ }^{4}$ Department of Public Health, School of Medicine, Universidad de los Andes, Bogota, Colombia

${ }^{5}$ Departamento de Física, Facultad de Ciencias, Universidad de Chile, Santiago de Chile, Chile

${ }^{6}$ Centro para el Desarrollo de la Nanociencia y la Nanotecnología, CEDENNA, Santiago de Chile, Chile

\section{Twitter Jose D Meisel @jdmeisel}

Contributors All authors had substantial contributions in the article. Particularly, JDM and OLS designed the study. JDM and VE did the analysis and interpretation of data. JDM, AMR, OLS, FM, IS and JAV led the writing of the report. OLS, JAV, FM, IS and AMR contributed in the analysis and interpretation of data. JDM and JAV developed the mathematical model fully described in the supplementary appendix. OLS, IS, AMR, VE and FM reviewed the mathematical model, and JDM implemented the model under the direction of JAV. Finally, all authors drafted sections of the 
report, provided critical review of the draft and approved the final version of the manuscript.

Funding This work was supported by project \#19-528-ESP of the joint grant of Research Offices at the Universidad de Los Andes and the Universidad de Ibagué FM was funded by NIH FIC D43TW010540 and by FAPA grant PR.3.2017.4527 of Universidad de los Andes. OLS received funding from the Administrative Department of Science, Technology and Innovation (Colciencias grant number726-2016) and Vicerrectoria de Investigaciones from Universidad de los Andes. JAV would like to thank Fondecyt grant 1190703 and the support of Centro para el Desarrollo de la Nanociencias y la Nanotecnología (CEDENNA)

Competing interests None declared.

Patient consent for publication Not required.

Ethics approval All the protocols were reviewed and approved by the Profamilia Institutional Review Board on Research Involving Human Subjects.

Provenance and peer review Not commissioned; externally peer reviewed.

Data availability statement All data relevant to the study are included in the article or uploaded as supplementary information. All data used in this study are within the paper and its supplementary files.

Open access This is an open access article distributed in accordance with the Creative Commons Attribution Non Commercial (CC BY-NC 4.0) license, which permits others to distribute, remix, adapt, build upon this work non-commercially, and license their derivative works on different terms, provided the original work is properly cited, appropriate credit is given, any changes made indicated, and the use is non-commercial. See: http://creativecommons.org/licenses/by-nc/4.0/.

ORCID iD

Jose D Meisel http://orcid.org/0000-0002-1032-0900

\section{REFERENCES}

$1 \mathrm{Ng} \mathrm{M}$, Fleming T, Robinson M, et al. Global, regional, and national prevalence of overweight and obesity in children and adults during 1980-2013: a systematic analysis for the global burden of disease study 2013. The Lancet 2014;384:766-81.

2 GBD 2015 Risk Factors Collaborators. Global, regional, and national comparative risk assessment of 79 behavioural, environmental and occupational, and metabolic risks or clusters of risks, 1990-2015: a systematic analysis for the global burden of disease study 2015. Lancet 2016;388:1659-724.

3 World Health Organization. Global status report on noncommunicable diseases 2014. WHO Library Cataloguing-in-Publication Data, 2014. Available: http://apps.who.int/iris/bitstream/handle/10665/148114/ 9789241564854_eng.pdf;jsessionid=97301FB348D75630E243392F DB4F5584? sequence $=1$

4 Monteiro CA, Conde WL, Lu B, et al. Obesity and inequities in health in the developing world. Int $\mathrm{J}$ Obes Relat Metab Disord 2004;28:1181-6.

5 Monteiro CA, Moura EC, Conde WL, et al. Socioeconomic status and obesity in adult populations of developing countries: a review. Bull World Health Organ 2004;82:940-6.

6 Dinsa GD, Goryakin Y, Fumagalli E, et al. Obesity and socioeconomic status in developing countries: a systematic review. Obes Rev 2012;13:1067-79.

7 McLaren L. Socioeconomic status and obesity. Epidemiol Rev 2007;29:29-48.

8 Abarca-Gómez L, Abdeen ZA, Hamid ZA, et al. Worldwide trends in body-mass index, underweight, overweight, and obesity from 1975 to 2016: a pooled analysis of 2416 population-based measurement studies in 128.9 million children, adolescents, and adults. The Lancet 2017;390:2627-42.

9 Jiwani SS, Carrillo-Larco RM, Hernández-Vásquez A, et al. The shift of obesity burden by socioeconomic status between 1998 and 2017 in Latin America and the Caribbean: a cross-sectional series study. Lancet Glob Health 2019;7:e1644-54.

10 Zavala JP, Leraç L, Vio F, et al. Actividad física y dieta saludable, percepción de peso y estrés en población adulta de Chile: Análisis de la encuesta de calidad de vida y salud 2006. Arch Latinoam Nutr 2010;60:319-25.

11 Monteiro CA, Conde WL, Popkin BM. Income-specific trends in obesity in Brazil: 1975-2003. Am J Public Health 2007;97:1808-12.

12 Schmidt MI, Duncan BB, Azevedo e Silva G, et al. Chronic noncommunicable diseases in Brazil: burden and current challenges. Lancet 2011;377:1949-61.
13 Parra DC, lannotti L, Gomez LF, et al. The nutrition transition in Colombia over a decade: a novel household classification system of anthropometric measures. Arch Public Health 2015;73:12.

14 Olszowy KM, Dufour DL, Bender RL, et al. Socioeconomic status, stature, and obesity in women: 20-year trends in urban Colombia. Am J Hum Biol 2012;24:602-10.

15 Meisel JD, Sarmiento OL, Olaya C, et al. Towards a novel model for studying the nutritional stage dynamics of the Colombian population by age and socioeconomic status. PLoS One 2018;13:e0191929:1-22.

16 Pérez-Ferrer C, McMunn A, Zaninotto P, et al. The nutrition transition in Mexico 1988-2016: the role of wealth in the social patterning of obesity by education. Public Health Nutr 2018;21:2394-401.

17 Tumas N, Rodríguez Junyent C, Aballay LR, et al. Nutrition transition profiles and obesity burden in Argentina. Public Health Nutr 2019;22:2237-47.

18 Jaacks LM, Vandevijvere S, Pan A, et al. The obesity transition: stages of the global epidemic. Lancet Diabetes Endocrinol 2019;7:231-40.

19 The World Bank Group. World Bank national accounts data, and OECD National Accounts data files. GDP (current US\$) - Colombia Data, 2018. Available: https://data. worldbank.org/indicator/NY.GDP. MKTP.CD?locations=CO [Accessed 24 Feb 2020].

20 The World Bank Group. GINI index (World Bank estimate) - Colombia | Data, 2017. Available: https://data.worldbank.org/indicator/SI.POV. GINI?contextual=region\&end=2017\&locations=CO\&most_recent value_desc=true\&start=2017\&type=shaded\&view=bar [Accessed 24 Feb 2020].

21 Instituto Colombiano de Bienestar Familiar ICBF. Encuesta Nacional de la Situación Nutricional en Colombia ENSIN. Bogotá: Instituto Colombiano de Bienestar Familiar ICBF, 2005.

22 Instituto Colombiano de Bienestar Familiar ICBF. Encuesta Nacional de la Situación Nutricional en Colombia ENSIN. Bogotá: Instituto Colombiano de Bienestar Familiar ICBF, 2010.

23 Lee BY, Bartsch SM, Mui Y, et al. A systems approach to obesity. Nutr Rev 2017;75:94-106.

24 Mabry PL, Bures RM. Systems science for obesity-related research questions: an introduction to the theme issue. Am J Public Health 2014;104:1157-9.

25 Sabounchi NS, Hovmand PS, Osgood ND, et al. A novel system dynamics model of female obesity and fertility. Am J Public Health 2014;104:1240-6.

26 Fallah-Fini S, Rahmandad H, Huang $\mathrm{TT}-\mathrm{K}$, et al. Modeling us adult obesity trends: a system dynamics model for estimating energy imbalance gap. Am J Public Health 2014;104:1230-9.

27 Abidin NZ, Mamat M, Dangerfield B, et al. Combating obesity through healthy eating behavior: a call for system dynamics optimization. PLOS ONE 2014;9:1-17.

28 Aktas G, Tellioğlu N, Barlas Y, et al. The 34th International System Dynamics Conference, July 2016,Delft, Netherlands Modeling the Long Term Dynamics of Obesity As a Societal Epidemic, 2016: 1-8.

29 Chen H-J, Xue H, Liu S, et al. Obesity trend in the United States and economic intervention options to change it: a simulation study linking ecological epidemiology and system dynamics modeling. Public Health 2018;161:20-8.

30 Fletcher A, Bonell C, Sorhaindo A. You are what your friends eat: systematic review of social network analyses of young people's eating behaviours and bodyweight. $J$ Epidemiol Community Health 2011:65:548-55.

31 Marks J, Barnett LM, Foulkes C, et al. Using social network analysis to identify key child care center staff for obesity prevention interventions: a pilot study. J Obes 2013;2013:1-9.

32 Conte KP, Groen S, Loblay V, et al. Dynamics behind the scale up of evidence-based obesity prevention: protocol for a multi-site case study of an electronic implementation monitoring system in health promotion practice. Implement Sci 2017;12:146.

33 Schaefer DR, Simpkins SD. Using social network analysis to clarify the role of obesity in selection of adolescent friends. Am J Public Health 2014;104:1223-9.

34 Shin H-S, Valente TW, Riggs NR, et al. The interaction of social networks and child obesity prevention program effects: the pathways trial. Obesity 2014;22:1520-6.

35 Hennessy E, Ornstein JT, Economos CD, et al. Designing an AgentBased model for childhood obesity interventions: a case study of ChildObesity180. Prev Chronic Dis 2016;13:E04.

36 Orr MG, Kaplan GA, Galea S. Neighbourhood food, physical activity, and educational environments and black/white disparities in obesity: a complex systems simulation analysis. J Epidemiol Community Health 2016;70:862-7.

37 Hammond RA, Ornstein JT. A model of social influence on body mass index. Ann N Y Acad Sci 2014;1331:34-42. 
38 Beheshti R, Jalalpour M, Glass TA. Comparing methods of targeting obesity interventions in populations: an agent-based simulation. SSM Popul Health 2017;3:211-8.

39 Morshed AB, Kasman M, Heuberger B, et al. A systematic review of system dynamics and agent-based obesity models: evaluating obesity as part of the global syndemic. Obes Rev 2019;20 Suppl 2:161-78

40 Meisel JD, Sarmiento OL, Olaya C, et al. A system dynamics model of the nutritional stages of the Colombian population. Kybernetes 2016;45:554-70.

41 Departamento Administrativo Nacional de Estadística. Series de población 1985-2020. Available: https://www.dane.gov.co/index.php/ estadisticas-por-tema/demografia-y-poblacion/series-de-poblacion [Accessed 24 Feb 2020].

42 World Health Organization. WHO child growth standards: Length/ height-for-age, weight-for-age, weight-for-length, weight-forheight and body mass index-for-age: methods and development. Geneva, 2006. Available: http://www.who.int/childgrowth/standards/ technical_report/en/index.html [Accessed 19 Feb 2013].

43 de Onis M, Onyango AW, Borghi E, et al. Development of a who growth reference for school-aged children and adolescents. Bull World Health Organ 2007;85:660-7.

44 Clinical guidelines on the identification, evaluation, and treatment of overweight and obesity in adults: Executive summary. expert panel on the identification, evaluation, and treatment of overweight in adults. Am J Clin Nutr 1998;68:899-917.

45 Departamento Administrativo Nacional de Estadística. Estadísticas Vitales. Available: https://www.dane.gov.co/index.php/estadisticaspor-tema/salud/nacimientos-y-defunciones [Accessed 24 Feb 2020].

46 Departamento Administrativo Nacional de Estadística (DANE). Movilidad Y migración. Available: https://www.dane.gov.co/index. php/estadisticas-por-tema/demografia-y-poblacion/movilidad-ymigracion [Accessed 17 Feb 2020].
47 Rutstein SO, Jonhson K. The DHS wealth index. DHS comparative reports No. 6. Calverton, MA: ORC Macro, 2004.

48 Fotso J-C, Kuate-Defo B. Measuring socioeconomic status in health research in developing countries: should we be focusing on households, communities or both? Soc Indic Res 2005;72:189-237.

49 Departamento Administrativo Nacional de Estadística. Gross domestic product per capita at current prices, base year 2005. Bogotá, 2018.

50 Linando AY, Socioeconomic LS-K. Dietary, nutrition, body weight and epidemiologic transitions: three nations at different stage of development. Prog Nutr 2018;20:602-15

51 Jones-Smith JC, Gordon-Larsen P, Siddiqi A, et al. Is the burden of overweight shifting to the poor across the globe? time trends among women in 39 low- and middle-income countries (1991-2008). Int J Obes 2012;36:1114-20.

52 Diez Roux AV, Slesinski SC, Alazraqui M, et al. A novel international partnership for actionable evidence on urban health in Latin America: LAC-Urban health and SALURBAL. Glob Chall 2019;3:1800013.

53 Sarmiento OL, Parra DC, González SA, et al. The dual burden of malnutrition in Colombia. Am J Clin Nutr 2014;100:1628S-35.

54 Gaffney LK, Lozano OD, Almanza A, et al. The implementation of a national physical activity intervention in Colombia. J Phys Act Health 2019;16:430-6

55 Vecino-Ortiz Al, Arroyo-Ariza D. A tax on sugar sweetened beverages in Colombia: estimating the impact on overweight and obesity prevalence across socio economic levels. Soc Sci Med 2018;209:111-6.

56 Departamento Administrativo Nacional de Estadística. Proyecciones de población., 2011. Available: https://www.dane.gov.co/index.php/ estadisticas-por-tema/demografia-y-poblacion/proyecciones-depoblacion [Accessed 20 Aug 2019].

57 World Data Bank. World development indicators | DataBank, 2018. Available: https://databank.worldbank.org/reports.aspx?source= World\%20Development\%20Indicators [Accessed 26 Aug 2019]. 